\title{
Correction to: A Primer on the Game Theory Behind the National Resident Matching Program for the Medical Educator and Student
}

Muhammad Maaz ${ }^{1,2}$

Published online: 8 May 2020

(C) International Association of Medical Science Educators 2020

\section{Correction to: Medical Science Educator} https://doi.org/10.1007/s40670-020-00955-8

In the original article, Table 2 inadvertently omitted the letter "F" in the bottom right column. Article is updated and the corrected table is shown:

Publisher's Note Springer Nature remains neutral with regard to jurisdictional claims in published maps and institutional affiliations.

The online version of the original article can be found at https://doi.org/ $10.1007 /$ s40670-020-00955-8

Muhammad Maaz

maazm@mcmaster.ca

1 Faculty of Health Sciences, McMaster University,

Hamilton, Ontario, Canada

2 Department of Economics, McMaster University, Hamilton, Ontario, Canada 
Table 2 Example of run-through of the Roth-Peranson algorithm (student-proposing deferred acceptance) per preferences from Table 1

\begin{tabular}{llll}
\hline Round & Proposals & Responses to proposals & Allocations at end of round \\
\hline 1 & A, E, F propose to H1 & H1 accepts A and E, rejects F & H: A, E \\
& B, D propose to H2 & H2 accepts B and D & H2: B, D \\
C proposes to H3 & H3 accepts C & H3: C \\
& & None: F \\
& F proposes to H2 & H2 reneges on D and accepts F instead & H1: A, E \\
& & H2: B, F \\
& & & H3: C \\
& & & None: D \\
& & & H1: A, E \\
& & & H2: B, F \\
& & H3: C, D \\
& & Algorithm terminates
\end{tabular}

